\title{
PEDIATRICS \\ Sharikadze O.V. \\ PARTICULAR QUALITIES OF THE TREATMENT IN PRE-SCHOOL AGE CHILDREN SENSITIZED TO HOUSE DUST MITES ALLERGEN
}

\author{
Shupyk National Medical Academy of Post-Graduate Education, Ukraine
}

\begin{abstract}
Background. This study determined the efficacy of sublingual allergen-specific immunotherapy (SLIT) in Ukrainian children younger than 5 years of age with allergic rhinitis and bronchial asthma sensitized to house dust mite allergens. Methods. A cohort prospective study was conducted over a two years period with assessment of the sensitization towards inhalant allergens, measured invivo by wheal size and number of positive reactions on the standard skin prick test (SPT). SPSS was used to analyse any statistical correlation. Results. A total of 125 atopic asthma or/and allergic rhinitis with the mean age of $4.11 \pm 0.83$ who were sensitized to house dust mites Dermatophagoides pteronyssinus and/or Dermatophagoides farina were included. 47 children received two-years SLIT to treat house dust mite allergies using standardized extract of sublingual allergens containing a mixture of house dust mites (Der. pteronyssinus and Der. farinae) in the correlation of 1(0,175 HEP):1(0,175 HEP) (Diater, Spain). These patients were mono-sensitized with Der. pteronyssinus and Der. farinae or were SPT poly-sensitized, but these patients only had house dust mite allergy symptoms. In this group the assessment of clinical efficacy of SLIT showed the significant differences in VAS before treatment and 6 months after its receiving. The symptom "nasal obstruction" was assessed as $2.3 \pm-1.6$ points at the beginning of the therapy, and the data reduced almost twice $(1.3 \pm-1.1)$; $P<0,05$ after 6 months of SLIT; then (12 and 24 months) it decreased to $0.91 \pm 0.9$ and $0.34 \pm 0.5 ; P<0,01$, correspondingly. Conclusion. This study has shown that using of SLIT in atopic asthma or/and allergic rhinitis children under 5 year sensitized to house dust mites is an effective and safe treatment method and allows to quickly (over the first 6 months of SLIT) control the symptoms. The data of comparative analysis in the group of patients who didn't receive SLIT has pointed to high frequency of disease symptom occurrence after the end of baseline therapy.
\end{abstract}

KeyWords: sublingual allergen-specific immunotherapy, children, bronchial asthma, allergic rhinitis, sensitization, allergens, Diater.

\section{INTRODUCTION}

High frequency and increasing number of allergic diseases all over the world indicate the necessity for further study of the problem that seems to have been wellstudied. The search of new possibilities to diagnose and therapy methods related to them are a strategic task which are determined by WAO for the next decade. A feature of allergic diseases in children is transformation of one form into the other. This process is characterized by relative instability of clinical manifestations of allergy when some symptoms regularly prevail over the other ones in a child $[2,7,12,16]$.

\section{Corresponding Author:}

Olena Sharikadze, MD, PhD, Professor Assistant of Department of Pediatrics No.1, Shupyk National Medical Academy of Post-Graduate Education, Ukraine.
There are many examples when patients are sensitized to several allergens at the same time. Sensitization to allergenic molecules is one of the main etiological factors in the pathogenesis of development of allergic inflammation. However, in many cases exposure to a particular allergen cannot be completely avoided. Available medical therapies are not always fully effective or well tolerated. $[8,14,15]$. The efficacy of ASIT in the treatment of allergic diseases of adults and children has been proven and it is represented by the results of numerous randomized double-blind placebo-controlled studies which have resulted in the issuance of the corresponding European and international guidelines $[3,11]$. But the treatment of children with the use of immunotherapy methods is being discussed [5,9,10,13]. First of all, it is connected to the issues of safety and administration convenience. A wide interest in the new forms of ASIT is also related to the situation of the appearance the symptoms disease which is characteristic for more advanced stages in early-age children. That is why the study 
of the issues related to timely prescription of SLIT (as a more comfortable and safe form for children) and the study of its effect on coming to control allergic symptoms and prevention of disease progression can be considered as one of the units of the strategic direction suggested by WAO.

\section{PURPOSES, SUBJECTS and METHODS:}

\subsection{Purpose}

The aim of this study was to evaluate the effectiveness of SLIT application in children under 5 with allergic rhinitis (AR) and bronchial asthma (BA), sensitized to domestic house dust mite allergens.

\subsection{Subjects \& Methods}

\section{Study population}

This cohort prospective study was conducted at the National Children Hospital "OHMATDYT" and Children Outpatient Clinic “OHMATDYT” in Kyiv, Ukraine. This study was performed over a two-year period starting from September 2013. The study involved children with diagnosed bronchial asthma or/and allergic rhinitis who presented to the clinic during this period. Clinical diagnosis AR and/or BA in the intermittent or mild persistent / moderate persistent form - controlled was determined following ICONs criteria (2012). The clinical parameters chosen for assessment of asthma control were: diurnal symptoms, nocturnal symptoms, limitation of activities, need for relievers or rescue medications, presence of exacerbations and measurement of peak expiratory flow (PEF) or forced expiratory volume (FEV1) (according to age) at the clinic visit.

Four hundred and fifty children aged 36 months - 5 years were examined. The inclusion criteria were: severe and/or uncontrolled BA, children who were treated SLIT at the previous stages, children who have contraindications to SLIT. According to inclusion criteria: age from 36 months to 5 years, clinical diagnosis AR and/or BA in the intermittent or mild persistent / moderate persistent form - controlled, determined following ICONs criteria (2012), sensitization to domestic allergens of house dust mites Der. pteronyssinus and/or Der. farinae 125 (27.7\%) atopic asthma or/and allergic rhinitis children were selected for further study (according to skin prick tests data).

All children were subjected to the following procedures: diagnostic procedure analysis (allergic history, skin prick test and specific lgE). Clinical monitoring was provided every 6-12-24 months during outpatient clinic visits. Skin prick tests, allergen specific IgE assessments, allergic history assessments (rhino-conjunctivitis symptoms, bronchial asthma episode, skin manifestation) and overall examinations were conducted.

Accordingly, patients were classified into two groups: I. Bronchial asthma or/and allergic rhinitis in children who received a two-year immunotherapy course using sublingual allergens containing a mixture of house dust mites (Der. pteronyssinus and/or Der. farinae) in the correlation of 1 (0,175 HEP):1(0,175 HEP) Diater, Spain

The control group included the children with house dust mite allergies, AR and/or bronchial asthma that only received symptomatic treatments and not SLIT. More detailed data are shown in Table 1.

The study protocol was approved by the Bioethical Commission of the Shupyk National Medical Academy of Postgraduate Education. Informed consent for research was given by the parents of all patients.

\section{Skin prick test}

Skin prick test was carried out on the flexor aspect of forearm avoiding the wrist and antecubital fossa. The forearm was coded with a marker pen for the allergens to be tested spacing the tests out at about $3 \mathrm{~cm}$. A drop of the extract was deposited on the indicated position. The skin was then pricked vertically through each drop using a standardized prick test needle (Immunolog). The extract solution was wiped away with a tissue paper. Result was read after 15 to 20 minutes. The following standard inhalant allergens (Diater-Laboratories, Spain) were tested: Der. pteronyssinus, Der. farinae, birch pollen, grass pollen, Artemisia, Ambrosia Alternaria, cat, dog. These extracts were used in all patients at the start of study and during follow up [6]. A solution of histamine hydrochloride in the 
concentration of $10 \mathrm{mg} / \mathrm{ml}$ and, $0.9 \%$ saline solution were used as positive and a negative test controls respectively. Skin reaction was assessed after 15 minutes, a specimen where a 3-mm-papule was formed or where papule exceeded the size of the negative test control by more than $3 \mathrm{~mm}$ was considered as a positive. These extracts were used in all patients at the start of study and during follow up.

Table 1:

The clinical patient characteristics

\begin{tabular}{|c|c|c|}
\hline Indicator & $\begin{array}{l}\text { Group I } \\
(\mathrm{n}=47)\end{array}$ & $\begin{array}{l}\text { Control group } \\
(\mathrm{n}=20)\end{array}$ \\
\hline $\begin{array}{l}\text { Sex, n (\%) } \\
\text { Male } \\
\text { Female }\end{array}$ & $\begin{array}{l}33(70.2) \\
14(29.8)\end{array}$ & $\begin{array}{l}13(65) \\
7(35)\end{array}$ \\
\hline $\begin{array}{l}\text { Age }(M \pm m) \text {, years } \\
\text { Age limits }\end{array}$ & $\begin{array}{c}4.11 \pm 0.83 \\
3-5\end{array}$ & $\begin{array}{c}4.3 \pm 1.2 \\
3-5\end{array}$ \\
\hline $\begin{array}{l}\text { Clinical symptoms, } \mathrm{n}(\%)^{*} \\
\text { Rhinitis } \\
\text { Rhinoconjunctivitis } \\
\text { Allergic asthma } \\
\text { Wheezing } \\
\text { Upper palate itching } \\
\text { Cough }\end{array}$ & $\begin{array}{c}41(87.2) \\
4(8.5) \\
16(34.0) \\
5(10.6) \\
2(4.2) \\
41(87.2)\end{array}$ & $\begin{array}{c}20(100) \\
3(15) \\
7(35) \\
- \\
- \\
17(85)\end{array}$ \\
\hline $\begin{array}{l}\text { The results of skin prick test } \\
\text { with allergens of house dust } \\
\text { mites (average diameter of } \\
\text { papule, } \mathrm{mm} \text { ) }\end{array}$ & $8.4 \pm 4.1$ & $7.9 \pm 3.27$ \\
\hline $\begin{array}{l}\text { Number of patients with } \\
\text { polyvalent sensitization, } n(\%) \\
\text { - according to the data of skin } \\
\text { prick test }\end{array}$ & $21(44.6)$ & $9(45)$ \\
\hline Monosensitized (\%) & $30(63.8)$ & $11(55)$ \\
\hline
\end{tabular}

*- symptom combination is possible

\section{Specific immunotherapy}

The study involved 47 children with bronchial asthma or/and allergic rhinitis who received a two-year immunotherapy course using sublingual allergens containing a mixture of house dust mites (Der. pteronyssinus and Der. farinae) in the correlation of $1(0,175$ HEP):1(0,175 HEP) Diater, Spain. Children of the first group (47) received SLIT according to the following treatment protocol: intake of the drug by 1 spraying into the sublingual area on a daily basis; and the initial phase lasted 6 months (the overall dose for a patient was 1,325-1,425 HEP), the maintenance phase lasted for subsequent 18 months (overall allergen dose was on average 3,900 HEP). After the first drug dose of medication was administered the patients stayed in the clinic under the supervision for $\mathbf{4 0}$ minutes, for detection and registration of possible adverse effects, and further the drug was administered independently by the parents, control over possible adverse effects was exercised online by the allergologist.

Four visits per year were planned for the patients over the period of observation, and, if necessary - an additional control visit was possible.

The patients of both groups underwent the baseline therapy under the protocols. If necessary, second generation anti-histamine drugs, inhalation beta-agonists, inhalant corticosteroids and leukotriene inhibitor were prescribed to control respiratory symptoms

Measurement of serum $r$ Der $p 1, r$ Der $p 2$ and $r$ Der p10 - specific IgE

The term Allergen component is used for products based on molecular allergens purified from either their natural source (native) or biotechnologically produced as recombinant proteins. By using tests for single allergenic components as a complement to more traditional IgE antibody tests, further clinically relevant information can be gained. Immuno CAP Allergen components are useful tools when investigating and explaining allergic reactions more in detail and to determine if they are caused by crossreacting IgE antibodies to different allergens.

Molecular diagnostics which used Immuno CAP (Phadia) was performed to identify major ( $r$ Der $p 1, r$ Der $p 2$ ) and minor allergens ( $r$ Der p10) of house dust mites $[1,4]$.

\section{Assessment of clinical findings}

The efficacy of SLIT was assessed by a combined visual analogue scale (VAS) including 6 indices of allergic rhinitis and bronchial asthma symptoms, namely: nasal obstruction, rhinorrhea, nasal discharge, sneezing, nasal itch and itch of mucosa in the oral pharynx area and cough. A 5point gradation of VAS was accepted: 0 points - "0" symp- 
toms; 1 point - minimum symptoms; 2 points - mild symptoms; 3 points - moderate symptoms; 4 points - severe symptoms. Graphic images were suggested (different variants of "smiles" as a visualization scale) taking into account the age of the examined patients. Besides that, patients' parents received recommendations on additional intake of symptomatic drugs (if necessary) during the whole examination period. Additional drug intake was recorded in a special diary. The necessity for a daily drug intake was assessed in the following way: 2 points - 1 pill $(5 \mathrm{mg}) /$ day of anti-histamine drug, 3 points - 2 inhalation of drug $(400 \mathrm{mkg}) /$ day of nasal inhalant corticosteroids, while 1 pill (4mg / 5mg) of leukotriene inhibitor drug for children with allergic BA was assessed as 5 points. Absence of the necessity to take the drug was evaluated as 0 points.

\section{Statistical analysis}

The data that met normal distribution criteria, such as age and disease duration, were analyzed using Student's ttest, for independent variables. Other non-parametric data were compared with the chi-square test. The summary odds ratio, 95\% confidence intervals and standard errors using random-effects models were also computed.

Statistical processing of the obtained results was made using the standard statistical package Statistical for Windows 7.0.

For the statistical significance of the results, we used a value of $a=0.05$. The $p$ value of the statistical test is used for accepting or rejection of the hypothesis ( $p \geq a$ : hypothesis is accepted; $p<a$ : hypothesis is rejected). All results were elaborated, documented and presented in absolute and relative numbers and with statistical results by using statistical markers.

\section{Adverse events}

Detailed information about adverse events was collected during the study on a form that recorded all events, irrespective of the participants' attitude to the drug medication and of mild, moderate or serious severity.

\section{RESULTS AND DISCUSSION}

The study showed that 125 children had positive skin prick test results for standard aeroallergens. Dust mites were the most common allergen causing skin test. At the same time most of the patients, 87 (69.6\%), were polysensitized, and showed different variants of sensitized. According to the positive frequency distribution of the specific aeroallergens, the top five aeroallergens were Der. pteronissinus (92.16\%), Der. farinae (86.23\%), Alternaria alternate $(50.73 \%)$, cat $(20.32 \%)$ and grass pollen $(19.4 \%)$. Furthermore, 38 (30.4\%) children were positive only to D. pteronyssinus and/or D. farina.

In the first group 30 (63.8) children were monosensitized to house dust mite 38 (52.6\%). Among the children there were 29 (96.7) cases that showed positive reaction to both D. pteronyssinus and/or D. farina. In the control group 11 (55\%) children were sensitized only to D. pteronyssinus and/or D. farina. Average data of the levels slgE to $r$ Der p1, $r$ Der p2 (major allergenic components) and to $r$ Der p 10 (minor allergenic components) and data SPT are given in Table 2.

In the group of poly-sensitized patients (87 children) molecular diagnostic was made for 21 patients (24.1\%). Eighteen children in the group of mono-sensitized and 66 children in the group of poly-sensitized patients refused to undergo because they had indeterminate results. The results of children examination are provided.

The findings of skin prick test and the data of molecular diagnostics in children with allergic rhinitis and allergic bronchial asthma Immunotherapy was administered to 47 children of the first group. After 6 months of therapy, the symptom "nasal obstruction" reduced almost two-fold (1.3 \pm-1.1$) ; P<0.05$; while 12 and 24 months later SLIT data was $0.91 \pm 0.9$ and $0.34 \pm 0.5 ; P<0.01$, correspondingly. Other indices were also characterized by a considerable reduction: cough before the therapy was $2.2 \pm 1.5-$ which was clinically manifested by moderately severe and severe cough symptoms in $60.8 \%$ of children, in particular, at night time and early in the morning, while follow-up observation showed a reliable $(P<0.05)$ symptom regression to $1.3 \pm 1.1$ 6 months later, $0.7 \pm 0.312$ months later, and $0.2 \pm 0.524$ months later. 
Table 2.

Comparison on SPT and slgE between the groups

\begin{tabular}{|c|c|c|c|c|c|}
\hline Groups of patients & $\begin{array}{l}\text { Skin prick tests, } \\
\text { average papule } \\
\text { diameter in } \mathrm{mm}\end{array}$ & $\begin{array}{l}\text { r Der p } 1, \mathrm{kUA} / \mathrm{L} \\
(\mathrm{M} \pm \mathrm{m})\end{array}$ & $\begin{array}{l}\text { r Der p 2, kUA/L } \\
(\mathrm{M} \pm \mathrm{m})\end{array}$ & r Der p $10, \mathrm{kUA} / \mathrm{L}$ & $\begin{array}{l}\text { Skin prick tests, } \\
\text { average papule } \\
\text { diameter in } \mathrm{mm}\end{array}$ \\
\hline $\begin{array}{l}\text { I group (mono-sensitized) } \\
(\mathrm{n}-30)\end{array}$ & $7.4 \pm 4.3$ & $13.2 \pm 9.8$ & $30.4 \pm 12.6$ & $0 / 01 \pm 0.009$ & $0.98 / 0.92$ \\
\hline $\begin{array}{l}\text { I group (poly-sensitized } \\
\text { children }(n-17)\end{array}$ & $6.1 \pm 3.8$ & $8.7 \pm 6.3$ & $12.7 \pm 8.5$ & $0.02 \pm 0.01$ & $0.83 / 0.72$ \\
\hline $\begin{array}{lll}\text { Control } & \text { group } & \text { (poly- } \\
\text { sensitized) } & (n-9)\end{array}$ & $6.4 \pm 3.7$ & $18.4 \pm 8.9$ & $13, .2 \pm 9.8$ & $0.01 \pm 0.008$ & $0.94 / 0.91$ \\
\hline
\end{tabular}

Thus, $56 \%$ had only minimal or mild symptom manifestation in the form of infrequent cough in the morning, without night awakenings by the end of the first year of therapy, and it almost disappeared by the end of the 2 nd year of therapy.
Nasal obstruction, rhinorrhea, sneezing, nasal mucosa itching, oral mucosa itching, nasal discharge and cough decreased in all of the patients who underwent immunotherapy (Table 3).

Table 3.

Data on visual analogue scale in children undergoing SLIT and the control group

\begin{tabular}{|c|c|c|c|c|c|c|c|c|}
\hline \multirow[t]{2}{*}{$\begin{array}{l}\text { Symptom, points } \\
(0-4)\end{array}$} & \multicolumn{4}{|c|}{$\begin{array}{c}1^{\text {st }} \text { group } \\
(n=47)\end{array}$} & \multicolumn{4}{|c|}{$\begin{array}{l}\text { Control group } \\
\qquad(\mathrm{n}=20)\end{array}$} \\
\hline & $\begin{array}{c}\text { Before } \\
\text { treatment }\end{array}$ & 6 months & 12 months & 24 months & $\begin{array}{c}\text { Before } \\
\text { treatment }\end{array}$ & 6 months & $\begin{array}{c}12 \\
\text { months }\end{array}$ & $\begin{array}{c}24 \\
\text { months }\end{array}$ \\
\hline Nasal obstruction & $2.3 \pm-1.6^{* *}$ & $1.3 \pm-1.1^{*}$ & $0.91 \pm 0.9^{*}$ & $0.34 \pm 0.5^{*}$ & $2.4 \pm 1.4$ & $2.4 \pm 1.2$ & $2.2 \pm 0.9$ & $2.2 \pm 0.8$ \\
\hline Rhinorrhea. & $2.2 \pm 0.9^{* *}$ & $0.5 \pm 0.5^{*}$ & $0.5 \pm 0.6^{*}$ & $0.2 \pm 0.4^{*}$ & $1.8 \pm 0.9$ & $1.3 \pm 0.8$ & $2.5 \pm 1.2$ & $2.2 \pm 1.1$ \\
\hline Sneezing & $1.83 \pm 1.4^{* *}$ & $0.5 \pm 0.5^{*}$ & $0.3 \pm 0.4^{*}$ & $0.34 \pm 0.5^{*}$ & $1.8 \pm 1.2$ & $0.9 \pm 0.5$ & $0.7 \pm 0.4$ & $1.3 \pm 0.9$ \\
\hline $\begin{array}{l}\text { Nasal mucosa itch- } \\
\text { ing, oral mucosa } \\
\text { itching }\end{array}$ & $0.2 \pm 0.9^{* *}$ & $0.08 \pm 0.9^{* *}$ & $0.04 \pm 0.2^{* *}$ & $0.04 \pm 0.2^{* *}$ & $0.04 \pm 0.2$ & $0.04 \pm 0.2$ & $0.04 \pm 0.2$ & $0.04 \pm 0.2$ \\
\hline Nasal discharge & $1.8 \pm 1.3^{* *}$ & $1.3 \pm 1.1^{* *}$ & $0.6 \pm 0.5^{*}$ & $0.4 \pm 0.13^{*}$ & $2.2 \pm 1.1$ & $1.5 \pm 0.7$ & $1.6 \pm 0.5$ & $2.2 \pm 0.9$ \\
\hline Cough & $2.2 \pm 1.5^{* *}$ & $1.3 \pm 0.09^{* *}$ & $0.7 \pm 0.3^{*}$ & $0.2 \pm 0.1^{*}$ & $2.6 \pm 1.3$ & $1.5 \pm 0.7$ & $1.6 \pm 0.4$ & $2.3 \pm 0.8$ \\
\hline
\end{tabular}

Moreover, after 2 years of immunotherapy, patients did not require any further medications. The study showed that there were no significant differences between mono- and poly-sensitized children of the first group $(p>0.05)$.

\section{DISCUSSION}

The study showed that SLIT was an effective treatment in children suffering from allergic respiratory diseases such as allergic rhinitis and asthma (less symptoms and less medication intake) in comparison with children treated with symptomatic drugs only. As of the date of the study, patients of both groups had similar indices in VAS symptoms. For example, the same as the symptoms of nasal obstruction and cough described above. Thus, at the beginning of the therapy the "cough" with the control group children amounted for $2.6 \pm 1.3$ points and did not significantly differ $(P>0.05)$ from that of the first-group children - 2.2 \pm 1.5 . And at the end of the second year of therapy there was a significant difference in the results between the groups: $0.2 \pm 0.1$ (1st group) and $2.3 \pm 0.8$ (control group) $(P<0.01)$. Recurrence of some symptoms in the control 
group showed the need for SLIT. According to the literature our study showed that the improvement in clinical outcome was observed in both mono-sensitized and polysensitized patients [13]. The efficacy of SLIT treatment was not influenced by the patient's age. As of the date of the study, patients of both groups had similar indicators in VAS symptoms.

One of the most important components of SLIT is the possibility of its safe administration which takes into account the risks of possible anaphylactic reactions and its tolerance with children. SLIT tolerance was assessed for the first-group children using a linear scale which was describe above. In particular, $57.4 \%$ of patients (and their parents) assessed SLIT tolerance as "good" and $31.9 \%$ as "very good". Thus, total result of good and very good tolerance made up 89.3\%, which proves high safety of treatment and absence of serious adverse reactions. During the whole period of observation there was no evidence of any severe drug-related allergic/anaphylactic reactions.

\section{Conflict of interests}

There is no conflict of interests.

\section{CONCLUSIONS}

This study has shown that SLIT administration with standardized medical allergens in atopic asthma or/and allergic rhinitis children under 5 year sensitized to domestic allergens of house dust mites is an effective and safe treatment method and allows to quickly (over the first 6 months of SLIT) control the symptoms. The findings of comparative analysis in the group of patients not receiving SLIT indicates high incidence of symptoms after the end of baseline therapy. Quite a number of unsolved issues related to SLIT administration in early-age children require further study of the given therapeutic direction.

\section{ACKNOWLEDGMENT:}

We sincerely thank our patients for their courage and interest

\section{REFERENCES}

1. Shupyk National Medical Academy of postgraduate education,Ukrainian Center for Scientific Medical Information and Patent License Activities. (2011). Algoritm vidboru pacientiv dlya allergenspecificheskoy imunoterapii (ASIT) [Algorithm for selecting patients for allergen specific immunotherapy (ASIT)] Guidelines, Kiev, P.311

2. Ohotnikova, E. (2008). Allergicheskiy marsh: svyaz pocoleniy e escalaciya allergii u detey [The allergic march: generations and escalation of allergies in children] Clinical Immunology Allergology Infectology, vol.4 (15).

3. Pavlova, K. (2012). Patogeneticheskaya terapia allergicheskaya zabolevaniy: vozmojnosty ASIT $v$ Rossii. Effectivnay farmacoterapiya [Pathogenetic therapy of allergic diseases: ASIN opportunities in Russia. Effective pharmacotherapy]. Allergology and Immunology, vol.2, pp. 54-58.

4. Sepiashvili, R., (2014). Consensus WAO-ARIAGA2LEN po moleculyrnoy diagnostike allergii. Memorandum Vsemirnoy organizacii po allergii [Consensus WAO-ARIAGA2LEN molecular diagnosis of allergies. Memorandum of the World Allergy Organization]. Allergology and Immunology, vol., pp. 5-17.

5. Barberi, S., Ciprandi, G., Verdbci, E. (2015). Effect of high-dose sublingual immunotherapy on respiratory infections in children allergic to house dust mite. Asia Pac Allergy, Vol. 5. -P 163-169.

6. Bousquet, J., Heinzerling, L., Bachert, C. (2012). Position Paper EAACI Practical guide to skin prick tests in allergy to aeroallergens Allergy. Vol. 67. -P 18-24.

7. Ciprandi, G., Tosca, M.A., Fasce, L. (2006). Allergic children have more numerous and severe respiratory infections than non-allergic children. Pediatr Allergy Immunol, Vol.17. - P.389-391.

8. Ciprandi, G., C. Incorvaia, I., Dell'Albani, Di Cara,. Barberi, S., Puccinelli, P., Frati, F. (2013). RINOBIT Study Group. Allergen immunotherapy may exert an extra-antiallergic activity in children . J Biol Regul Homeost Agents. Vol.27.- P. 1053-1057.

9. Canonica, G.W. (2014). Sublingual immunotherapy: World Allergy Organization position paper 
2013 update. World Allergy Organ J., Vol.7. -4-18.

10. Cox, L. (2001). Sublingual immunotherapy for aeroallergens: status in the United States . Allergy Asthma Proc. Vol. 35. - P.34-42.

11. Dhami, S., Dhami, S., Nurmatov, U. (2016). Allergen Immunotherapia for allergic asthma protocol for a systematic rewiew. Clin Transl Allergy. Retrieved from: http: //ctajournal.biomedcentral.com.

12. Kusel, M.M., Kebadze, T., Johnston, S.L., Holt, P.G., Sly, P.D. (2012). Febrile respiratory illnesses in infancy and atopy are risk factors for persistent asthma and wheeze. Eur Respir J. Vol. 39. - P. 876-882.

13. Linkov, G., Toskala, E. (2014). Sublingual immunotherapy: what we can learn from the European experience. Curr Opin Otolaryngol Head Neck Surg. Vol.22. - P. 208-210.

14. Papadopoulos, N.G., Arakawa, H., Carlsen, K.H. (2012). Position Paper International consensus on (ICON) pediatric asthma . Allergy. Vol.67.P.976-997

15. Szefler, S.J. (2014). Advances in pediatric asthma in 2013: coordinating asthma care. J Allergy Clin. Vol.14.P324-325

16. Wahn, V. (2000). What drives the allergic march? Allergy. Vol. 55. - P. 591-599.

Received: 11-Jan. - 2017

Accepted: 23-Apr. - 2017 